\title{
COMPARING PHENOTYPIC VARIATION OF ROOT TRAITS IN THAI RICE (ORYZA SATIVA L.) ACROSS GROWING SYSTEMS
}

\author{
SAENGWILAI, P. ${ }^{1,2^{*}}$ - KlinSAWANG, $S .{ }^{1}-$ SANGACHART, M. ${ }^{1}$ - BUCKSCH, A. ${ }^{3,4,5}$ \\ ${ }^{1}$ Department of Biology, Faculty of Science, Mahidol University \\ Bangkok 10400, Thailand \\ ${ }^{2}$ Center of Excellence on Environmental Health and Toxicology (EHT) \\ Bangkok, Thailand \\ ${ }^{3}$ Department of Plant Biology, University of Georgia \\ Athens, GA, 30602, USA \\ ${ }^{4}$ Warnell School of Forestry and Natural Resources, University of Georgia \\ Athens, GA, 30602, USA \\ ${ }^{5}$ Institute of Bioinformatics, University of Georgia \\ Athens, GA, 30602, USA \\ *Corresponding author \\ e-mail: patompong.sae@mahidol.edu; phone:+66-9-1725-4817
}

(Received $8^{\text {th }}$ Sep 2017; accepted $15^{\text {th }}$ Jan 2018)

\begin{abstract}
Root systems have long been neglected in plant breeding due to their inaccessibility and the laborious nature of root studies. Over the past years, root scientists developed the classification system, methodologies and growing systems for high throughput measurements of root traits. We compared root traits obtained with three growing systems for eleven Thai rice varieties. We found considerable differences in the variation of root traits between the laboratory system with paper roll-up, a pot system in the greenhouse and a field system. The variation of root traits ranged from 1.31 folds in root cortical aerenchyma (RCA) to 4.20 folds in crown root growth angle in a roll-up system. Varieties also differed in root plasticity among the three growing environments. Principal components analysis indicated that root anatomical traits contributed 55\% to the observed variation in the field. Hierarchical cluster analysis revealed that upland varieties clustered in a steep-angled group while lowland varieties clustered in a shallow-angled group. The observed clustering could be linked to the amount of RCA. Our results suggest that optimization of root growth angle could be an important strategy for improved adaptation of rice plants growing in flooded and non-flooded areas. We propose Thai rice varieties as donors in root trait driven breeding programs to enhance water and nutrient uptake.
\end{abstract}

Keywords: breeding, $R C A$, root system, varieties

\section{Introduction}

Rice (Oryza sativa) is a staple crop for over 3.5 billion people (IRRI et al., 2010) and an economic driver for many countries in south and southeast Asia. A prime example of the economic importance of rice is Thailand (Wailes and Chavez, 2012) with 25 million tons produced on paddy fields in 2016. Rice production depends on high water availability and highly fertile soils; however, one-third of the global rice production area is planted in nutrient deficient soils (Haefele et al., 2014). In addition, ongoing climate change and a predicted fertilizer shortage limit resource availability for rice production (Haefele et al., 2006). This scenario poses significant economic challenges to large- and small-scale rice farmers. Improved rice varieties with 
enhanced capability of water and nutrient uptake efficiency are one of the solutions to drought and nutrient limited growth conditions.

Root systems play important roles in water and nutrient acquisition of a plant as well as anchorage to support the plant structure. Continuous shoot improvements of the last decades neglected the phenotypic variation of root architectural, morphological, and anatomical traits despite the widely available genetic resources. The key to understand the potential of root phenotypes lies in the understanding of root structure and function relative to its developmental processes on architectural and anatomical scale (Lynch, 2007; Lynch, 2014). Rice root architecture consists of five root types including the embryonic and the postembryonic roots such as the radicle, the embryonic crown roots, the postembryonic crown roots, the large lateral roots, and the small lateral roots (Rebouillat et al., 2008). Variation in root architecture has been shown to positively influence soil exploration and acquisition of water and nutrients in nutrient limited and drought conditions. For instance, rice promotes deep rooting which enhances growth and yield under drought (Uga et al., 2013) similar to wellknown observations in maize under drought and low nitrogen conditions (Hund et al., 2009; Saengwilai et al., 2014b; Trachsel et al., 2013). Under phosphorus (P) stress, root traits that describe shallow foraging strategies increase the acquisition of immobile $\mathrm{P}$ in the topsoil, e.g. shallow rooting angle and high lateral branching density (Lynch and Brown, 2001; Zhu and Lynch, 2004).

Root hairs constitute the finest architectural level. They are tip-growing extensions from root epidermal cells (Datta et al., 2011). Root hair development is not purely dependent on the genotype, but also depends on environmental factors such as soil texture, type and level of nutrients in soils (Gilroy and Jones, 2000). The ability to adapt to different environmental conditions is measurable as surface area of root hairs that increases the contact with the soil. As a consequence, more surface contact with the soil increases efficiency of nutrient uptake capacity (Gilroy and Jones, 2000; Miguel et al., 2015).

Rice root anatomy summarizes the internal organization of cell and tissue types. The components of the internal arrangement are root epidermis, exodermis, schlerenchyma layer, cortex, endodermis, pericycle, cortical aerenchyma and xylem and phloem vessels. Anatomical traits have been hypothesized to deliver major improvements in crop production through improving resource capture, transport, and utilization (Lynch, 2014; Postma and Lynch, 2010). For example, smaller diameter of xylem vessels improved water use efficiency by conserving water resources for grain filling in wheat (Richards and Passioura, 1989). Another example is reduced cortical cell file number and increased cortical cell size, which led to reduced root respiration and increased rooting depth in maize. As a consequence, improved water acquisition and greater yield under drought was observed (Chimungu et al., 2014a; 2014b). The formation of root cortical aerenchyma (RCA) improves crop growth and productivity under drought and suboptimal nitrogen conditions in maize (Saengwilai et al., 2014a; Zhu et al., 2010).

Root traits have been studied in various growing systems. Among culturing approaches, a roll-up or cigar-roll and a greenhouse pot system have been commonly used for phenotyping roots of several crop species. The roll-up system allows for a rapid, low cost, and non-destructive evaluation of root traits in young seedlings. In addition, the roll-up system is capable to observe delicate traits such as root hair length and density (Zhu et al., 2005). A pot system using soil permits a more realistic condition for root growth in a controlled environment and is widely used for genetics and 
physiological studies in rice (Vejchasarn et al., 2016). In the field, shovelomics, a manual high throughput approach, facilitates the evaluation of mature root architecture (Trachsel et al., 2011). Although studies have demonstrated significant correlations of root traits in different culture systems (Tuberosa et al., 2002), such comparisons in rice are still scarce. To assist breeding efforts towards improved drought tolerance and higher yield under nutrient limited growth conditions, a better understanding of root traits among rice varieties in different growing systems is much needed. In our study, we aim to 1) investigate phenotypic variation of root architectural and anatomical traits in eleven Thai rice varieties with low-cost phenotyping technologies and to 2) examine correlations among root traits and growing conditions.

\section{Materials and methods}

\section{Plant materials}

Rice (Oryza sativa L.) is a member of Poaceae family and the common cultivated varieties are annual plants that grow up to two meters tall. Rice cultivation occurs in different types of managed ecosystems such as irrigated, rainfed upland, rainfed lowland, flood-prone systems. In our study, eleven Thai rice varieties were selected because of their popularity among Thai farmers, variation in growing system, and potential as donors in rice breeding program. The varieties include photoperiod sensitive lowland varieties (Khao Dawk Mali 105 (KDML105), Niaw San-pah-tawng, RD13), photoperiod insensitive lowland varieties (RD1, Phitsanulok 2, RD7 and RD31), photoperiod sensitive upland varieties (Goo Meuang Luang, Nam Roo and Leum Pua) and photoperiod insensitive upland varieties (R258). Seeds were obtained from the Rice Department of the Ministry of Agriculture and Cooperatives of Thailand.

\section{Growth conditions}

\section{Roll-up system}

The laboratory experiment was carried out at the Phayathai campus of Mahidol University, Bangkok, Thailand (13 $\left.45^{\prime} 54.3^{\prime \prime N} 100^{\circ} 31^{\prime} 35.4^{\prime \prime E}\right)$. Seeds were surface sterilized in $10 \% \mathrm{NaOCl}$ for $1 \mathrm{~min}$. The seeds were put in a rolled germination paper (Anchor Paper Company, St. Paul, MN, USA) soaked with 0.5 millimolars (mM) $\mathrm{CaSO}_{4}$ and placed in darkness at 28 degree Celsius $\left({ }^{\circ} \mathrm{C}\right)$ in a germination chamber for two days then exposed to supplement lights and harvested at 7 days after germinating.

\section{Greenhouse pot system}

The greenhouse experiment was carried out at the Salaya campus of Mahidol University, Nakhon Pathom, Thailand (134ㄱ'40.2"N 100'19'26.7"E). Seeds of lowland rice varieties including KDML105, Phitsanulok 2, RD13, RD31, and RD7 were surfacesterilized in $10 \% \mathrm{NaOCl}$ for $1 \mathrm{~min}$. The seeds were pre-germinated in rolled germination papers (Anchor Paper Company, St. Paul, MN, USA) soaked with $0.5 \mathrm{mM}$ $\mathrm{CaSO}_{4}$ and placed in the darkness at $28^{\circ} \mathrm{C}$ for two days. At planting, the plants were transferred to 10 Liter (L) pots with growth media consisting of a mixture (volume based) of $50 \%$ medium size (0.3 to 0.5 Milliliters $(\mathrm{mm})$ ) commercial grade sand, $35 \%$ horticultural vermiculite, $15 \%$ Perlite. One day before planting, the pots were saturated with 3 liters of a nutrient solution adjusted to $\mathrm{pH}$. The nutrient solution contained (in 
$\mu \mathrm{M}): \mathrm{NO}_{3}$ (7000), $\mathrm{NH}_{4}(1000), \mathrm{P}(1000), \mathrm{K}$ (3000), $\mathrm{Ca}(2000), \mathrm{SO}_{4}(500), \mathrm{Mg}(500), \mathrm{Cl}$ (25), B (12.5), Mn (1), Zn (1), Cu (0.25), Mo (0.25) and FeDTPA (100). Each pot received three seedlings and after 4 days, the plants were thinned to one plant per pot. Plants were watered with $75 \mathrm{ml}$ of deionized water every other day until harvest.

\section{Field study}

The field experiment was carried out on a research farm in the Tha Yang district located in the Petchaburi province of western Thailand $\left(12^{\circ} 56^{\prime} 37.3^{\prime \prime} \mathrm{N} 99^{\circ} 55^{\prime} 24.1^{\prime \prime} \mathrm{E}\right)$ (Fig. 1). The soil in Tha Yang is classified as loamy sand which are derived from residuum on hill slopes with a layer of angular rock fragments occurring within $50 \mathrm{~cm}$ of the surface. The average ambient temperature during the study was $27 \pm 2{ }^{\circ} \mathrm{C}$ and the relative humidity was $90 \%$. The five lowland rice varieties were selected for this experiment. The trail was arranged in a randomized complete block design (RCBD) with three replications. The seeds were sawn in wet seed beds for 30 days and then transplanted into the field. Each variety was planted in three-row plots. Each plot consisted of 12 plants. Row width was 12 centimeters $(\mathrm{cm})$, and the distance within a row was $12 \mathrm{~cm}$. Water was maintained in the rice field to suppress weed growth during the growing season. In the trial, soil nutrient levels of were adjusted to meet the requirements for rice production as determined by soil tests at the beginning of the growing seasons. The trial was managed according to typical farmer practice.

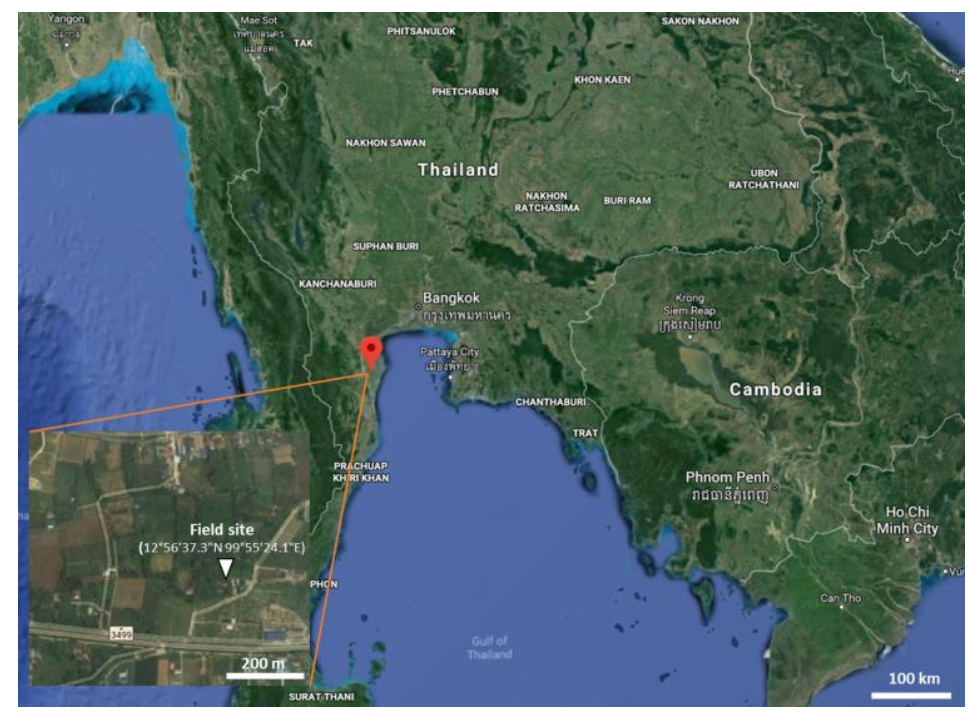

Figure 1. A satellite image of the field experimental site in Tha Yang district, Petchaburi province, Thailand (modified from Map data (C2018 Google)

\section{Shoot and root analyses}

Prior to root excavation, shoot characteristics including tiller numbers and height were assessed. Root excavation was carried with the shovelomics protocol described in Trachsel et al. (2010) and Vejchasarn et al. (2016). Root crowns were collected by excavating a $15-\mathrm{cm}$ radius around the stem to a depth of at least $15 \mathrm{~cm}$. The majority of soil was removed by carefully shaking the root system. The remaining soil was removed by soaking the roots in diluted commercial detergent for 8-12 hours. In a final step we rinsed the soaked root systems with water using a a low pressure garden hose. A Four- 
centimeter root segment was collected at $8 \mathrm{~cm}$ from the base of the representative nodal roots for morphological and anatomical analyses. The samples were stored in $75 \%$ EtOH at $4^{\circ} \mathrm{C}$ until processing and analysis.

\section{Root architectural analysis}

For the roll-up system, root architectural traits were manually evaluated by counting numbers of roots, and by measurements obtained with a ruler. Root architectural traits including crown root growth angle, crown root number, lateral root branching and lateral root length were evaluated using a modified Shovelomics protocol for the pot and field experiment. Our protocol evaluated crown root growth angle with a scoring board and manually counted the number of crown roots. We quantified lateral root branching as a count of lateral roots in a two-centimeter segment starting at $8 \mathrm{~cm}$ offset of the root base. Lateral root length was measured with a ruler. Shoots and roots were dried at $60^{\circ} \mathrm{C}$ for $72 \mathrm{~h}$ prior to weight determination. The measurements were carried out with 4 replications and 4 sub-replications per sample.

\section{Root morphological analysis}

Root hair evaluation was carried out as described by Vejchasarn et al. (2016). Primary root or crown root samples were stained with $0.5 \%$ of toluidine blue for $45 \mathrm{~s}$ before the images of the root hairs were taken. We used the imaging system MVX10 of the Macro Zoom to obtain root hair images. Root hair length was measured in the obtained images with Image-J version 1.46 (Abràmoff et al., 2004) and root hair density was measured by counting the number of root hairs in the one-millimeter root segment.

\section{Root anatomical analysis}

Root segments were selected from the middle of the crown root samples and preserved in $75 \% \mathrm{EtOH}$ at $4{ }^{\circ} \mathrm{C}$ until processing and analysis. Root cross-sections were obtained by free hand-sectioning using Teflon-coated double-edged stainless-steel blades. The root sections were examined with a light microscope at $2.8 \mathrm{x}$ magnification. Three sections were selected to be imaged as representative sub-samples . Root anatomical traits were quantified using the semi-automated image analysis program RootScan (Burton et al., 2012). All together eight root anatomical traits were evaluated in this study (Table 1).

Table 1. Abbreviations and descriptions of traits measured in this study

\begin{tabular}{c|c|c|c}
\hline Trait & Description & Trait & Description \\
\hline TRL & Total root length, cm & TSA & Total stele area, $\mathrm{mm}^{2}$ \\
RW & Root weight, $\mathrm{g}$ & AA & Aerenchyma area, $\mathrm{mm}^{2}$ \\
LB & Lateral root branching on radicle & perAA & Percent of cortex as aerenchyma, \% \\
LL & Lateral root length on radicle & MXVA & Metaxylem vessel area, $\mathrm{mm}^{2}$ \\
CA & Crown root angle & CCFN & Cortical cell file number \\
CB & Crown root branching & CCC & Cortical cell count \\
CN & Crown root number & RHL & Root hair length, mm \\
RXSA & Root cross sectional area, $\mathrm{mm}^{2}$ & RHD & Root hair density \\
TCA & Total cortical area, $\mathrm{mm}^{2}$ & SW & Shoot weight, $\mathrm{g}$ \\
\hline
\end{tabular}




\section{Statistical analysis}

Statistical analysis was performed using $\mathrm{R}$ version 2.15.1. Linear mixed effect models were fit using the lme function from the package nlme (Pinherio et al., 2012). ANOVA was used to compare varieties as well as upland and lowland characteristics. The protected least significant difference post hoc $(\alpha=0.05)$ was used for multiple comparison tests. Correlations and a principal component analysis were performed on mean values of the measurements taken per genotype.

\section{Results}

\section{Natural variation among root traits and growing systems}

Significant phenotypic variation between the selected varieties was observed in all experiments for anatomical and architectural traits. In the roll-up system, varieties significantly differed in their shoot and root traits (Table 2).

Table 2. Summary of phenotypic variation of root traits (Table 1) showing mean, range, and significant level among 11 commercial and traditional varieties of Thai rice in the roll-up system

\begin{tabular}{|c|c|c|c|c|c|c|c|c|}
\hline Variety & TRL & RW & $\mathbf{C A}$ & $\mathrm{CN}$ & LB & $\mathbf{L L}$ & RHD & RHL \\
\hline \multirow{4}{*}{$\begin{array}{c}\text { Goo Meuang Luang } \\
\text { KDML105 } \\
\text { Leum Pua } \\
\text { Nam Roo }\end{array}$} & $20.05 \mathrm{a}$ & $0.06 \mathrm{~cd}$ & $55.63 \mathrm{a}$ & $5.31 \mathrm{bcd}$ & $17.58 \mathrm{a}$ & $0.74 \mathrm{ab}$ & $31.54 \mathrm{ab}$ & $0.19 \mathrm{ab}$ \\
\hline & $17.56 \mathrm{ab}$ & $0.04 \mathrm{f}$ & $28.46 \mathrm{e}$ & $4.31 \mathrm{e}$ & $16.11 \mathrm{ab}$ & $0.57 \mathrm{cb}$ & $34.01 \mathrm{a}$ & $0.18 \mathrm{a}$ \\
\hline & $18.29 \mathrm{ab}$ & $0.07 \mathrm{~b}$ & $14.06 \mathrm{f}$ & $4.31 \mathrm{e}$ & $16.33 \mathrm{ab}$ & $0.36 \mathrm{ef}$ & $31.61 \mathrm{ab}$ & $0.16 \mathrm{ef}$ \\
\hline & $16.89 \mathrm{ab}$ & $0.07 \mathrm{~b}$ & $28.67 \mathrm{~cd}$ & $5.33 \mathrm{bcd}$ & $17.63 \mathrm{a}$ & $0.44 \mathrm{def}$ & $31.70 \mathrm{ab}$ & $0.19 \mathrm{ab}$ \\
\hline \multirow{3}{*}{$\begin{array}{c}\text { Niaw San-pah-tawng } \\
\text { Phitsanulok } 2 \\
\text { R258 }\end{array}$} & $12.99 \mathrm{~b}$ & $0.06 \mathrm{bc}$ & $21.47 \mathrm{~d}$ & $5.53 \mathrm{bcd}$ & $10.67 \mathrm{~b}$ & $0.32 \mathrm{f}$ & $34.86 \mathrm{a}$ & $0.21 \mathrm{a}$ \\
\hline & $14.99 \mathrm{ab}$ & $0.05 \mathrm{e}$ & $34.67 \mathrm{c}$ & $5.80 \mathrm{bc}$ & $15.67 \mathrm{ab}$ & $0.47 \mathrm{de}$ & $26.27 \mathrm{~b}$ & $0.18 b c$ \\
\hline & $13.57 \mathrm{ab}$ & $0.09 \mathrm{a}$ & $59.00 \mathrm{a}$ & $5.10 \mathrm{cde}$ & $15.13 \mathrm{ab}$ & $0.31 \mathrm{f}$ & $29.07 \mathrm{ab}$ & $0.19 \mathrm{ab}$ \\
\hline RD1 & $15.97 \mathrm{ab}$ & $0.07 \mathrm{~b}$ & $36.67 \mathrm{bc}$ & $6.50 \mathrm{ab}$ & $14.80 \mathrm{ab}$ & $0.60 \mathrm{bcd}$ & $28.00 \mathrm{ab}$ & $0.14 \mathrm{f}$ \\
\hline RD13 & $15.46 \mathrm{ab}$ & $0.04 \mathrm{f}$ & $50.00 \mathrm{ab}$ & $4.71 \mathrm{de}$ & $15.75 \mathrm{ab}$ & $0.39 \mathrm{ef}$ & $30.73 \mathrm{ab}$ & $0.16 \mathrm{de}$ \\
\hline RD31 & $17.27 \mathrm{ab}$ & $0.05 \mathrm{f}$ & $22.00 \mathrm{~cd}$ & $6.83 \mathrm{a}$ & $16.37 \mathrm{a}$ & $0.61 \mathrm{bc}$ & $28.84 \mathrm{ab}$ & $0.17 \mathrm{~cd}$ \\
\hline RD7 & $17.84 \mathrm{ab}$ & $0.04 \mathrm{f}$ & $28.06 \mathrm{~cd}$ & $6.33 \mathrm{ab}$ & $15.56 \mathrm{ab}$ & $0.80 \mathrm{a}$ & $30.56 \mathrm{ab}$ & $0.19 \mathrm{bc}$ \\
\hline Range & $1.41 \mathrm{x}$ & $2.12 \mathrm{x}$ & $4.20 \mathrm{x}$ & $1.58 \mathrm{x}$ & $1.65 \mathrm{x}$ & $2.58 \mathrm{x}$ & $1.33 \mathrm{x}$ & $1.50 \mathrm{x}$ \\
\hline Significance & $*$ & $*$ & $*$ & $*$ & * & 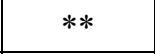 & $* *$ & $*$ \\
\hline Variety & RSXA & TCA & TSA & $\mathbf{A A}$ & perAA & MXVA & CCFN & SW \\
\hline Goo Meuang Luang & 0.17 bcde & 0.15 bcdef & $0.015 \mathrm{bcd}$ & 0.043 cde & $28.19 \mathrm{~b}$ & $0.0006 \mathrm{e}$ & $8.67 \mathrm{ab}$ & $2.16 \mathrm{~b}$ \\
\hline KDML105 & 0.16 cde & 0.15 cdef & $0.012 \mathrm{def}$ & $0.050 \mathrm{cde}$ & $33.24 \mathrm{ab}$ & 0.0007 cde & $7.33 \mathrm{~b}$ & $4.14 \mathrm{~b}$ \\
\hline Leum Pua & $0.26 \mathrm{a}$ & $0.24 \mathrm{a}$ & $0.024 \mathrm{a}$ & $0.081 \mathrm{a}$ & $34.02 \mathrm{ab}$ & $0.0015 \mathrm{a}$ & $9.33 \mathrm{ab}$ & $2.44 \mathrm{~b}$ \\
\hline Nam Roo & $0.20 \mathrm{bc}$ & $0.18 \mathrm{bc}$ & $0.019 \mathrm{bc}$ & $0.059 \mathrm{bcd}$ & $32.28 \mathrm{ab}$ & $0.0012 \mathrm{bc}$ & $9.00 \mathrm{ab}$ & $3.66 \mathrm{~b}$ \\
\hline Niaw San-pah-tawng & $0.18 \mathrm{bcd}$ & $0.17 \mathrm{bcd}$ & 0.014 cde & $0.060 \mathrm{bc}$ & $36.09 \mathrm{a}$ & $0.0010 \mathrm{bcd}$ & $9.33 \mathrm{ab}$ & $8.03 \mathrm{a}$ \\
\hline Phitsanulok 2 & $0.15 \mathrm{de}$ & 0.14 def & $0.011 \mathrm{def}$ & $0.040 \mathrm{de}$ & $29.16 \mathrm{~b}$ & $0.0006 \mathrm{de}$ & $9.67 \mathrm{ab}$ & $1.88 \mathrm{~b}$ \\
\hline R258 & $0.18 \mathrm{bcd}$ & 0.16 bcde & $0.019 \mathrm{bc}$ & 0.047 cde & $30.76 \mathrm{ab}$ & $0.0012 \mathrm{~b}$ & $9.33 \mathrm{ab}$ & $2.52 \mathrm{~b}$ \\
\hline RD1 & 0.16 cde & 0.15 cdef & $0.012 \mathrm{def}$ & 0.049 cde & $32.82 \mathrm{ab}$ & $0.0006 \mathrm{e}$ & $9.00 \mathrm{ab}$ & $2.11 \mathrm{~b}$ \\
\hline RD13 & $0.18 \mathrm{bcd}$ & $0.17 \mathrm{bcd}$ & $0.015 \mathrm{bcd}$ & $0.060 \mathrm{bc}$ & $35.40 \mathrm{a}$ & $0.0008 \mathrm{cde}$ & $9.33 a b$ & $1.92 \mathrm{~b}$ \\
\hline RD31 & $0.13 \mathrm{e}$ & $0.2 \mathrm{f}$ & $0.010 \mathrm{f}$ & $0.038 \mathrm{e}$ & $32.03 \mathrm{ab}$ & $0.0005 \mathrm{e}$ & $9.33 \mathrm{ab}$ & $3.12 \mathrm{~b}$ \\
\hline RD7 & $0.21 \mathrm{~b}$ & $0.19 \mathrm{~b}$ & $0.017 \mathrm{bc}$ & $0.069 \mathrm{ac}$ & $36.88 \mathrm{a}$ & $0.001 \mathrm{bc}$ & $10.00 \mathrm{a}$ & $4.12 \mathrm{~b}$ \\
\hline Range & $2.05 x$ & $2.02 x$ & $2.40 x$ & $2.14 x$ & $1.31 \mathrm{x}$ & $2.9 \mathrm{x}$ & $1.36 \mathrm{x}$ & $4.27 \mathrm{x}$ \\
\hline Significance & $* *$ & $* *$ & $* *$ & $* *$ & $* *$ & $* *$ & $* *$ & $*$ \\
\hline
\end{tabular}

$*$, ** and $* * *$ denote significances at $0.05,0.01$ and 0.001 . Different letters represent significant difference. Maximum and minimum values are highlighted in dark and light color, respectively. The reported range value denotes to the $\mathrm{x}$-fold difference between maximum and minimum values for each trait 
The range of shoot dry weight (SW) was substantial, showing a 4.27-fold increase between smallest and largest average value per genotype. The identified extremal varieties are Niaw San-pah-tawng and Phitsanulok 2. For architectural root traits, a remarkable 4.20-fold increase between extrema was observed for the crown root angle (CA). The extremal variation for anatomical traits was 1.31-fold in the percentage of aerenchyma (perAA). Generally, the ranges of the variation in anatomical root traits were higher than those of root architectural traits. Leum Pua, a traditional upland variety, had largest cross-sectional area (RXSA) of $0.26 \mathrm{~mm}^{2}$ on average with high aerenchyma area (AA) of $0.081 \mathrm{~mm}^{2}$ on average. In contrast, the lowland variety RD 31 had the smallest RXSA roots $\left(0.13 \mathrm{~mm}^{2}\right.$ on average $)$ with smaller AA $\left(0.038 \mathrm{~mm}^{2}\right.$ on average) compared to upland varieties.

In the pot system, five lowland varieties including KDML105, Phitsanulok 2, RD13, RD31, and RD7 were selected for this set of experiment to compare traits among varieties grown under optimal growth conditions. We found that varieties significantly differed in their shoot and root traits except for root hair density (RHD) and cortical cell file number (CCFN) (Table 3). Among those with significant differences, the variation of root traits ranged from 1.25-fold in total root length (TRL) to 2.28-fold in lateral root branching of the crown root (CB). KDML105 was most outstanding in its anatomical traits showing the thickest roots with large metaxylem vessel area (MXVA) and highest aerenchyma formation (AA and perAA). Phitsanulok 2 had the lowest AA, perAA and smallest MXVA. The ranking for anatomical traits of these two varieties were consistent across growing systems (Table 2 and 3). Unfortunately, the root segments of RD13 dried out during the storage process and could not be evaluated.

Table 3. Summary of phenotypic variation of root traits (Table 1) showing mean, range, and significant level among 5 lowland rice varieties in the pot system

\begin{tabular}{c|c|c|c|c|c|c|c|c}
\hline Variety & SW & TRL & CA & CN & LB & LL & RHD & RHL \\
\hline KDML105 & $27.27 \mathrm{ab}$ & $45.50 \mathrm{~b}$ & $40.00 \mathrm{a}$ & $271.33 \mathrm{bc}$ & $41.00 \mathrm{a}$ & $4.79 \mathrm{ab}$ & 17.50 & $0.09 \mathrm{~b}$ \\
Phitsanulok2 & $24.35 \mathrm{~b}$ & $42.88 \mathrm{bc}$ & $37.50 \mathrm{ab}$ & $263.00 \mathrm{c}$ & $27.38 \mathrm{~b}$ & $4.99 \mathrm{ab}$ & 22.33 & $0.18 \mathrm{a}$ \\
RD31 & $30.39 \mathrm{ab}$ & $50.10 \mathrm{a}$ & $37.50 \mathrm{ab}$ & $334.00 \mathrm{ab}$ & $19.25 \mathrm{c}$ & $3.91 \mathrm{~b}$ & 33.00 & $0.10 \mathrm{~b}$ \\
RD7 & $28.51 \mathrm{ab}$ & $42.75 \mathrm{bc}$ & $32.50 \mathrm{~b}$ & $369.00 \mathrm{a}$ & $24.88 \mathrm{bc}$ & $5.73 \mathrm{a}$ & 22.50 & $0.10 \mathrm{~b}$ \\
RD13 & $35.54 \mathrm{a}$ & $40.00 \mathrm{c}$ & $27.50 \mathrm{~b}$ & $408.00 \mathrm{a}$ & $18.00 \mathrm{c}$ & $5.53 \mathrm{ab}$ & & \\
\hline Range & $1.46 \mathrm{x}$ & $1.25 \mathrm{x}$ & $1.45 \mathrm{x}$ & $1.55 \mathrm{x}$ & $2.28 \mathrm{x}$ & $1.47 \mathrm{x}$ & $1.89 \mathrm{x}$ & $2.00 \mathrm{x}$ \\
Significance & $*$ & $*$ & $*$ & $*$ & $*$ & $* *$ & $\mathrm{NS}$ & $*$ \\
\hline Variety & RXSA & TCA & TSA & AA & perAA & MXVA & CCFN & CCC \\
\hline KDML105 & $0.79 \mathrm{a}$ & $0.74 \mathrm{a}$ & $0.06 \mathrm{a}$ & $0.42 \mathrm{a}$ & $56.19 \mathrm{a}$ & $0.005 \mathrm{a}$ & 10.83 & $550.00 \mathrm{ab}$ \\
Phitsanulok2 & $0.57 \mathrm{~b}$ & $0.35 \mathrm{~b}$ & $0.05 \mathrm{a}$ & $0.19 \mathrm{~b}$ & $37.70 \mathrm{~b}$ & $0.003 \mathrm{~b}$ & 10.89 & $671.80 \mathrm{a}$ \\
RD31 & $0.52 \mathrm{~b}$ & $0.48 \mathrm{~b}$ & $0.04 \mathrm{~b}$ & $0.27 \mathrm{~b}$ & $54.19 \mathrm{a}$ & $0.004 \mathrm{~b}$ & 10.33 & $459.40 \mathrm{~b}$ \\
RD7 & $0.54 \mathrm{~b}$ & $0.49 \mathrm{~b}$ & $0.04 \mathrm{~b}$ & $0.27 \mathrm{~b}$ & $53.31 \mathrm{a}$ & $0.004 \mathrm{~b}$ & 10.89 & $530.70 \mathrm{ab}$ \\
\hline Range & $1.52 \mathrm{x}$ & $2.11 \mathrm{x}$ & $1.50 \mathrm{x}$ & $2.21 \mathrm{x}$ & $1.49 \mathrm{x}$ & $1.67 \mathrm{x}$ & $1.05 \mathrm{x}$ & $1.46 \mathrm{x}$ \\
Significance & $* *$ & $* *$ & $* *$ & $* *$ & $* *$ & $* *$ & $\mathrm{NS}$ & $*$ \\
\hline
\end{tabular}

$*, * *$ and $* * *$ denote significances at $0.05,0.01$ and 0.001 . NS means no significant difference. Different letters represent significant difference. Maximum and minimum values are highlighted in dark and light color, respectively. The reported range value denotes to the $\mathrm{x}$-fold difference between maximum and minimum values for each trait 
The five varieties grown in the pot system were also evaluated in the field at 60 days after transplanting. We found that varieties significantly differed in their shoot and root traits except for RHD, perAA and grain yield (Table 4). Among those with significant genotypic differences, the variation of root traits ranged from 1.39-fold in $\mathrm{CB}$ to 2.14fold in AA. Despite considerable variation in AA, perAA appeared to be high and not significantly different among varieties. Among all varieties, the photoperiod-sensitive lowland variety, RD13, showed consistently shallower root systems with the largest number of crown roots $(\mathrm{CN})$ in the pot system and in the field. Additionally, Phitsanulok 2 maintained its ranking as having low AA with relatively small MXVA (Table 3 and 4).

Table 4. Summary of phenotypic variation of root traits (Table 1) showing mean, range, and significant level among 5 lowland rice varieties grown in the field

\begin{tabular}{c|c|c|c|c|c|c|c|c}
\hline Variety & SW & TN & CA & CB & CN & RHL & RHD & $\begin{array}{c}\text { Grain } \\
\text { (g/plant) }\end{array}$ \\
\hline KDML105 & $13.91 \mathrm{a}$ & $5.56 \mathrm{a}$ & $23.89 \mathrm{~b}$ & $2.74 \mathrm{ab}$ & $205.30 \mathrm{a}$ & $0.09 \mathrm{ab}$ & $12.78 \mathrm{a}$ & - \\
Phitsanulok 2 & $6.66 \mathrm{c}$ & $4.56 \mathrm{ab}$ & $35.83 \mathrm{~b}$ & $3.04 \mathrm{a}$ & $154.00 \mathrm{~b}$ & $0.08 \mathrm{~b}$ & $8.67 \mathrm{a}$ & $1.98 \mathrm{a}$ \\
RD13 & $13.51 \mathrm{a}$ & $4.56 \mathrm{ab}$ & $25.83 \mathrm{a}$ & $2.74 \mathrm{ab}$ & $228.40 \mathrm{a}$ & $0.09 \mathrm{ab}$ & $13.56 \mathrm{a}$ & - \\
RD31 & $6.00 \mathrm{c}$ & $3.89 \mathrm{~b}$ & $31.39 \mathrm{ab}$ & $2.41 \mathrm{ab}$ & $134.40 \mathrm{~b}$ & $0.07 \mathrm{~b}$ & $9.38 \mathrm{a}$ & $1.74 \mathrm{a}$ \\
RD7 & $9.61 \mathrm{~b}$ & $4.89 \mathrm{ab}$ & $29.44 \mathrm{ab}$ & $2.19 \mathrm{~b}$ & $211.30 \mathrm{a}$ & $0.11 \mathrm{a}$ & $9.67 \mathrm{a}$ & $2.52 \mathrm{a}$ \\
Range & $2.32 \mathrm{x}$ & $1.43 \mathrm{x}$ & $1.50 \mathrm{x}$ & $1.39 \mathrm{x}$ & $1.70 \mathrm{x}$ & $1.57 \mathrm{x}$ & $1.56 \mathrm{x}$ & $1.45 \mathrm{x}$ \\
Significance & $* * *$ & $* *$ & $* *$ & $*$ & $* *$ & $* *$ & $\mathrm{NS}$ & $\mathrm{NS}$ \\
\hline Variety & RXSA & TCA & TSA & AA & perAA & MXVA & CCFN & CCC \\
\hline KDML105 & $0.93 \mathrm{~b}$ & $0.90 \mathrm{a}$ & $0.03 \mathrm{a}$ & $0.53 \mathrm{~b}$ & $58.11 \mathrm{a}$ & $0.0031 \mathrm{a}$ & $11.80 \mathrm{a}$ & $212.57 \mathrm{~b}$ \\
Phitsanulok 2 & $0.68 \mathrm{~b}$ & $0.65 \mathrm{~b}$ & $0.02 \mathrm{ab}$ & $0.37 \mathrm{~b}$ & $57.55 \mathrm{a}$ & $0.0021 \mathrm{~b}$ & $9.13 \mathrm{ab}$ & $146.13 \mathrm{c}$ \\
RD13 & $1.43 \mathrm{a}$ & $1.40 \mathrm{a}$ & $0.03 \mathrm{a}$ & $0.79 \mathrm{a}$ & $55.85 \mathrm{a}$ & $0.0032 \mathrm{a}$ & $9.67 \mathrm{a}$ & $331.17 \mathrm{a}$ \\
RD31 & $0.68 \mathrm{~b}$ & $0.65 \mathrm{~b}$ & $0.02 \mathrm{ab}$ & $0.38 \mathrm{~b}$ & $57.55 \mathrm{a}$ & $0.0020 \mathrm{~b}$ & $6.22 \mathrm{~b}$ & $160.00 \mathrm{bc}$ \\
RD7 & $0.71 \mathrm{~b}$ & $0.69 \mathrm{~b}$ & $0.02 \mathrm{~b}$ & $0.38 \mathrm{~b}$ & $53.04 \mathrm{a}$ & $0.0021 \mathrm{~b}$ & $9.89 \mathrm{a}$ & $195.50 \mathrm{bc}$ \\
\hline Range & $2.10 \mathrm{x}$ & $2.15 \mathrm{x}$ & $1.5 \mathrm{x}$ & $2.14 \mathrm{x}$ & $1.10 \mathrm{x}$ & $1.52 \mathrm{x}$ & $1.90 \mathrm{x}$ & $2.27 \mathrm{x}$ \\
Significance & $* *$ & $* *$ & $* *$ & $* *$ & $\mathrm{NS}$ & $*$ & $* *$ & $* * *$ \\
\hline
\end{tabular}

$*$, ** and $* * *$ denote significances at $0.05,0.01$ and 0.001 . NS means no significant difference. Different letters represent significant difference. Maximum and minimum values are highlighted in dark and light color, respectively. The reported range value denotes to the $\mathrm{x}$-fold difference between maximum and minimum values for each trait

\section{Correlation analysis}

Correlation analysis was performed for root traits in the roll-up, pot, and field system. In the roll-up system, anatomical traits showed strong positive correlations with correlation coefficient values (r) ranging from 0.70 to 1.00 (Table 5). Smaller correlation values were observed for perAA which was only positively correlated with aerenchyma area $(r=0.70 ; p<0.05)$ and cortical cell file number $(\mathrm{CCFN})$. The crown root number $(\mathrm{CN})$ observed in the roll-up system showed a marginally negative correlation with total stele area (TSA) and metaxylem vessel area (MXVA) $(r=-0.53 ; \mathrm{p}$ $<0.1)$. However, this relationship disappeared in plants grown in the pots and in the field (Table 5). 
Table 5. Correlation matrix among root traits of 11 commercial and traditional Thai rice varieties grown in the roll-up system and five lowland varieties grown in the pot and the field system

\begin{tabular}{|c|c|c|c|c|c|c|c|c|c|c|c|}
\hline $\begin{array}{l}\text { Roll-up } \\
\text { system }\end{array}$ & RXSA & TCA & TSA & $\mathbf{A A}$ & perAA & MXVA & CCFN & $\mathrm{CCC}$ & CA & $\mathbf{C N}$ & PB \\
\hline TCA & $1.00 * * *$ & & & & & & & & & & \\
\hline TSA & $0.93 * * *$ & $0.91 * * *$ & & & & & & & & & \\
\hline $\mathbf{A A}$ & $0.94 * * *$ & $0.95 * * *$ & $0.79 * *$ & & & & & & & & \\
\hline perAA & 0.41 & 0.44 & 0.33 & $0.70^{*}$ & & & & & & & \\
\hline MXVA & $0.90 * * *$ & $0.88^{* * *}$ & $0.94 * * *$ & $0.81 * *$ & 0.36 & & & & & & \\
\hline CCFN & 0.23 & 0.23 & 0.22 & 0.25 & 0.21 & 0.26 & & & & & \\
\hline $\mathrm{CCC}$ & $0.88 * * *$ & $0.89 * * *$ & $0.70^{*}$ & $0.88^{* * * *}$ & 0.47 & $0.68 *$ & 0.31 & & & & \\
\hline CA & -0.25 & -0.27 & -0.10 & -0.40 & -0.44 & -0.22 & 0.11 & -0.18 & & & \\
\hline $\mathbf{C N}$ & -0.51 & -0.5 & -0.53 & -0.41 & 0.19 & -0.53 & 0.48 & -0.38 & -0.11 & & \\
\hline PB & 0.56 & 0.18 & 0.16 & -0.1 & -0.49 & -0.11 & -0.22 & -0.10 & 0.21 & -0.21 & \\
\hline RHL & 0.17 & -0.2 & 0.12 & -0.23 & -0.17 & 0.13 & 0.07 & -0.22 & 0.13 & -0.10 & -0.30 \\
\hline Pot system & CN & CA & LB & LL & RXSA & TSA & AA & MXVA & TCA & $\begin{array}{c}\text { perA } \\
\mathbf{A}\end{array}$ & \\
\hline CA & $0.91 *$ & & & & & & & & & & \\
\hline LB & -0.73 & 0.68 & & & & & & & & & \\
\hline $\mathbf{L L}$ & 0.44 & -0.67 & 0.11 & & & & & & & & \\
\hline RXSA & -0.58 & 0.66 & $0.97 *$ & 0.10 & & & & & & & \\
\hline TSA & -0.90 & 0.58 & 0.80 & -0.22 & 0.70 & & & & & & \\
\hline $\mathbf{A A}$ & 0.19 & 0.45 & 0.75 & 0.12 & 0.86 & 0.24 & & & & & \\
\hline MXVA & -0.33 & 0.59 & 0.85 & 0.16 & 0.94 & 0.42 & $0.98 *$ & & & & \\
\hline TCA & -0.11 & 0.41 & 0.74 & 0.09 & 0.84 & 0.21 & $1.000^{* * *}$ & $0.97 *$ & & & \\
\hline perAA & 0.49 & 0.11 & 0.17 & 0.17 & 0.33 & -0.44 & 0.77 & 0.62 & 0.79 & & \\
\hline CCFN & -2.38 & 0.28 & 0.56 & 0.87 & 0.37 & 0.67 & 0.10 & 0.18 & 0.11 & -0.36 & \\
\hline Field system & RXSA & TCA & TSA & $\mathbf{A A}$ & perAA & MXVA & CCFN & $\mathrm{CCC}$ & RHL & $\mathrm{CA}$ & CB \\
\hline TCA & $1.00 * * *$ & & & & & & & & & & \\
\hline TSA & 0.47 & 0.45 & & & & & & & & & \\
\hline $\mathbf{A A}$ & $1.00 * * *$ & $1.00 * * *$ & 0.51 & & & & & & & & \\
\hline perAA & 0.18 & 0.04 & 0.79 & 0.11 & & & & & & & \\
\hline MXVA & 0.85 & $0.85 *$ & 0.77 & $0.87 *$ & 0.25 & & & & & & \\
\hline CCFN & 0.34 & 0.34 & 0.35 & 0.35 & -0.06 & 0.66 & & & & & \\
\hline $\mathrm{CCC}$ & $0.98^{* *}$ & $0.98^{* *}$ & 0.31 & $0.97 * *$ & -0.24 & 0.79 & 0.35 & & & & \\
\hline RHL & 0.14 & 0.11 & 0.42 & 0.15 & 0.14 & 0.28 & 0.34 & 0.13 & & & \\
\hline $\mathrm{CA}$ & -0.65 & -0.65 & -0.53 & -0.67 & -0.01 & -0.78 & -0.59 & -0.70 & -0.73 & & \\
\hline CB & 0.25 & 0.24 & 0.59 & 0.26 & 0.67 & 0.44 & 0.25 & -0.12 & -0.40 & 0.18 & \\
\hline $\mathrm{CN}$ & 0.71 & 0.71 & 0.10 & 0.70 & -0.51 & 0.69 & 0.75 & 0.80 & 0.22 & -0.75 & -0.11 \\
\hline
\end{tabular}

$*$, ** and *** denote significances at $0.05,0.01$ and 0.001

In pots, perAA and CCFN were not correlated with any other root traits (Table 5). We collected crown root traits for mature rice plants at 60 days after transplanting and found that crown root growth angle (CA) was negatively correlated with $\mathrm{CN}(\mathrm{r}=-0.91$; $\mathrm{p}<0.05)$. Our observation suggests that varieties with fewer crown roots were steeper 
than varieties with more crown root number. Moreover, we found that lateral root branching was positively correlated with root cross sectional area (RXSA) or root size (r $=-0.97 ; \mathrm{p}<0.05)$. Hence, the larger the root segments the more lateral root density can be observed. Similar results were found in the field where anatomical traits were positively correlated among each other except for aerenchyma and CCFN traits (Table 5). However, the relationship between $\mathrm{CA}$ and $\mathrm{CN}$ was negative but not significant. In addition, correlation analysis was performed for the five low-land varieties grown in all three systems (Table 6). We found strong but marginally significant relationships between the experimental systems. Root anatomical traits including RXSA, TCA, and AA were correlated between traits measured in the pot and the field $(r=0.95 ; p<0.1)$. In addition, root hair density (RHD) was correlated between the roll-up system and the field $(\mathrm{r}=0.90, \mathrm{p}<0.1)$.

Table 6. Correlation coefficient and p values for Spearman-rank correlation analysis between root traits measured in the roll-up, the pot, and in the field of 5 Thai rice varieties

\begin{tabular}{c|c|c|c|c}
\hline Trait & Description & Roll-up:Pot & Pot:Field & Field:Roll-up \\
\hline RSXA & Root cross sectional area, $\mathrm{mm}^{2}$ & 0.80 & $0.95^{*}$ & 0.67 \\
TCA & Total cortical area, $\mathrm{mm}^{2}$ & 0.60 & $0.95^{*}$ & 0.67 \\
TSA & Total stele area, $\mathrm{mm}^{2}$ & -0.20 & 0.77 & 0.29 \\
AA & Aerenchyma area, $\mathrm{mm}^{2}$ & 0.60 & $0.95^{*}$ & 0.41 \\
perAA & Percentage of cortex as aerenchyma, \% & 0.40 & 0.63 & -0.67 \\
MXVA & Metaxylem vessel area, $\mathrm{mm}^{2}$ & -0.40 & 0.32 & 0.56 \\
CCFN & Cortical cell file number & -0.40 & 0.00 & -0.21 \\
CCC & Cortical cell count & -0.20 & -0.40 & 0.30 \\
RHL & Root hair length, mm & -0.32 & -0.60 & 0.50 \\
RHD & Root hair density & -0.40 & -0.40 & $0.90^{*}$ \\
CA & Crown root angle & -0.82 & -0.05 & 0.30 \\
CB & Crown root branching & -0.10 & 0.31 & 0.05 \\
CN & Crown root number & 0.10 & 0.70 & -0.50 \\
\hline
\end{tabular}

${ }^{*}$ denotes significances at $\mathrm{P}<0.1$

\section{Principal component analysis}

Principal component analysis (PCA) was performed separately on the mean values of root traits for the plants grown in the roll-up, the pot, and the field system. Based on the variable loadings, principal component 1 was predominantly composed of anatomical traits. Biplots of the first and second components showed similar trends in trait structure in all growing systems (Fig. 2). perAA and CCFN were independent from other anatomical traits. The results from correlation analysis show the same independance.

\section{Hierarchical cluster analysis}

Hierarchical cluster analysis was performed for the root traits measured in the roll-up experiment. Certain traits had more pronounced influences and determined cluster membership. Strongly clustered traits included metaxylem vessel area, percentage of aerenchyma, root growth angle, and lateral root branching (Fig. 3). Leum Pua variety was distinguished from other rice varieties by its large diameter xylem vessel $(0.0015$ 
$\mathrm{mm}^{2}$ ). Other than Leum Pua variety, the varieties with low perAA were clustered by crown root growth angle. The crown root growth angle further clustered upland and lowland varieties. A shallow angle classified lowland rice varieties and a steep angle identifies to upland varieties (Fig. 3).
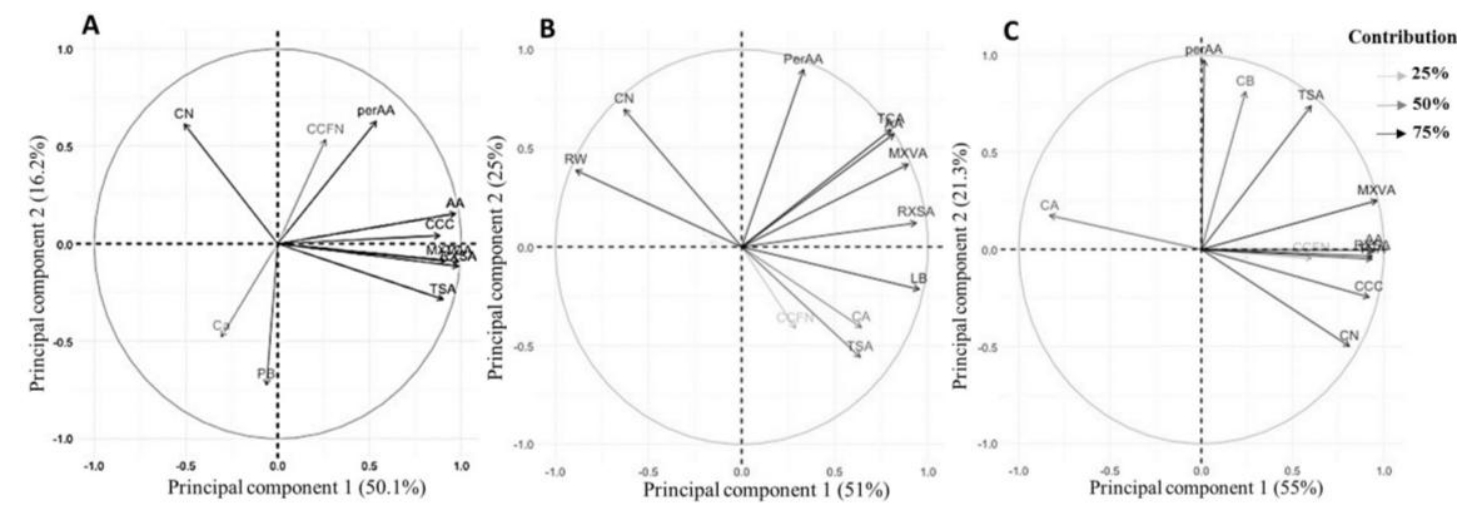

Figure 2. Biplots of principal components analysis for root traits in (A) 11 commercial and traditional varieties grown in the roll-up system (B) 5 lowland varieties grown in the pot system and $(C)$ in the field system

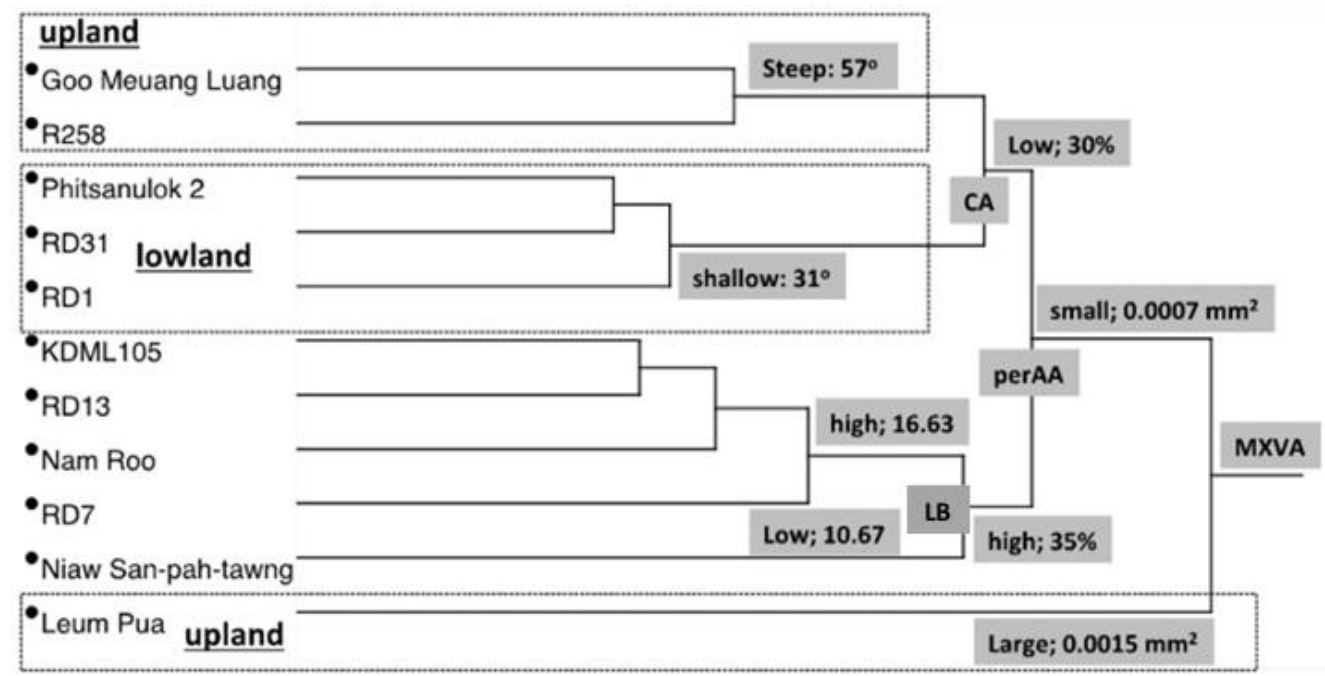

Figure 3. Hierarchical clustering analysis with the Ward cluster method. Root anatomical, morphological and architectural traits of 11 Thai rice varieties grown in the roll-up system are shown. Mean values of the traits are denoted within gray boxes per cluster group. See Table 1 for abbreviations and descriptions of root traits

\section{Discussion}

We observed large phenotypic variation for anatomical and architectural root traits in popular Thai rice varieties. The variation was investigated for eleven traditional and commercial Thai rice varieties in the roll-up system and for five lowland rice varieties in the pot and the field system. We found that the variation of root traits ranged from 1.31-fold in root cortical aerenchyma (RCA) to 4.20-fold in crown root growth angle in the roll-up system (Table 2). The major contribution of the variation within a root 
system came from anatomical traits. We found evidence for this contribution in the results of the principal component analysis in which anatomical traits clustered into one group and contributed the major portion to the first principle component (Fig. 2). Similar trends were found in root systems of other monocots such as the Zea species (Burton et al., 2013). Anatomical variation related to differences in performance and stress response in many crop species, including maize (Saengwilai et al., 2014a), common bean (Peña-Valdivia et al., 2010) and rice (Henry et al., 2012). Variation in the number and diameter of xylem vessels is known to strongly affect axial water conductance and potentially enhance water use efficiency under terminal drought (Lynch et al., 2014). In wheat, it has been shown that narrow xylem vessels enhance wheat adaptation under drought and has been used in wheat breeding programs to improve drought tolerance (Richards and Passioura, 1989). In case of rice, the reverse was proposed, namely that less axial resistance in roots would favor water acquisition from deeper soil layers (Yambao et al., 1992). In our study, we found that variation in the size of metaxylem vessel was substantial. The results from hierarchical clustering analysis indicate that metaxylem vessel area in our data set was the first major factor differentiating rice varieties into different groups (Fig. 3). Among the varieties, Leum Pua, an upland variety, had two-fold larger metaxylem vessel area than the average of the rest of the data set in the roll-up system. Other upland varieties such as Goo Meuang Luang and R258 appeared to have small metaxylem area; however, these varieties have steep root system which could enhance deep soil exploration in the upland environments. We suggest that root growth angle might be important strategy for adaptation to stress enviroments.

We suggest that deep rooting may be associated with the adaptation under drought conditions by drought avoidance. Several root traits have been shown to contribute to deep rooting such as high root cortical aerenchyma (Saengwilai et al., 2014a), reduced crown root number (Saengwilai et al., 2014b), and low lateral root branching (Zhan et al., 2015). In rice, expression of DEEPER ROOTING 1 gene (DRO1) causing a steeper root growth angle that results in an overall deeper root system with increased yield in drying soils (Uga et al., 2013). In our study, we found that upland varieties such as Goo Meuang Luang and R258 had steep root growth angle of more than 50 degree from horizon whereas lowland varieties had much shallower growth angle in the roll-up system. The five low land varieties planted in the pot and field system maintained their shallow root growth angle. Similar to the results reported in other monocot studies (Trachsel et al., 2013; Uga et al., 2013), we propose that root growth angle could be a promising trait for plant breeding programs that can be screened already at the seedling stage.

While many of the traits measured in cross-sections were found to be highly correlated with one another, we observed that the percentage of aerenchyma and root hair length was independent from some anatomical root traits and whole root characteristics. These results suggest that these traits are feasible for rice breeding program because breeders could pyramid aerenchyma and root hair length with other root and shoot traits without complications. Correlations greater than 0.95 were observed between cortical components such as RXSA, TCA, and AA. Strong positive correlations may mean that these traits share measurement elements, and offer overlapping information. In particular, metaxylem vessel area was positively correlated to total stele area. It has been reported that stele and xylem might be controlled by various genetic factors and correlation between the total stele area and metaxylem 
vessel area can be attributed either to a tight linkage of the QTLs for traits or to pleiotropy of one QTL (Uga et al., 2008). Our results suggest that the efficiency of root phenotyping can be improved by eliminating such redundant traits and/or replacing redundant traits with traits that correlate weakly with other parameters.

Traits correlation between the three experimental systems was weak. We expected weak correlations because plants in each system correspond to different ages, developmental stages, and different environments. Overall, the demonstrated strong variations in root traits suggest ample opportunities for plant breeders to develop new varieties by using existing Thai germplasm. Varieties such as KDML 105 have high market values and therefore they are popular among Thai farmers. Hence, it is possible to maximize water and nutrient use efficiency by considering root traits in irrigation and fertilizer regimes.

\section{Conclusion}

Characterization of the structural and functional diversity of root traits is an important step for plant breeding. Breeders may be reluctant to utilize exotic donors in their programs because of the risk to loose important traits for enhanced enviromental adaption. However, our results suggested that traits of Thai rice roots vary considerable and hold an unused potential for plant breeding programs. We see ample opportunity for introgression of our investigated traits into elite rice varieties by using Thai germplasms as parents. We recommend that upland varieties particularly Goo Meuang Luang and R258 could be used as donors for steep root angle which could enhance drought tolerance while Leum Pua, a traditional variety, could serve as a donor for enhanced water acquisition by increasing metaxylem area. Further experiments of the physiological utility of rice root traits in edaphic stresses are required to pin point more beneficial root traits and to identify new rice ideotypes. The future challenge is to identify molecular markers associated with variation of root traits to enhance efficiency and effectiveness of plant breeding programs.

Acknowledgement. We thank members of MUSC Root lab, Phytoremediation research and Root Laboratory, Faculty of Science, Mahidol University for their assistance throughout the project. This research project is supported by Mahidol University.

\section{REFERENCES}

[1] Abràmoff, M. D., Magalhães, P. J., Ram S. J. (2004): Image processing with Image - J. Biophotonics International 11: 36-42.

[2] Burton, A. L., Brown, K. M., Lynch, J. P. (2013): Phenotypic diversity of root anatomical and architectural traits in Zea species. - Crop Science 53: 1042-1055.

[3] Chimungu, J. G., Brown, K. M., Lynch, J. P. (2014a): Reduced root cortical cell file number improves drought tolerance in maize. - Plant Physiology 166: 1943-1955.

[4] Chimungu, J. G., Brown, K. M., Lynch J. P. (2014b): Large root cortical cell size improves drought tolerance in maize. - Plant Physiology 166: 2166-2178.

[5] Datta, S., Kim, C. M., Pernas, M., Pires, N. D., Proust, H., Tam, T., Vijayakumar, P., Dolan, L. (2011): Root hairs: development, growth and evolution at the plant-soil interface. - Plant and Soil 346: 1-14. 
[6] Gilroy, S., Jones, D. L. (2000): Through form to function: root hair development and nutrient uptake. - Trends in Plant Science 1385: 56-60.

[7] Haefele, S. M., Naklang, K., Harnpichitvitaya, D. (2006): Factors affecting rice yield and fertilizer response in rainfed lowlands of northeast Thailand. - Field Crops Research 98: 39-51.

[8] Haefele, S. M., Nelson, A., Hijmans, R. J. (2014): Soil quality and constraints in global rice production. - Geoderma 235-236: 250-259.

[9] Henry, A., Cal, A. J., Batoto, T. C. (2012): Root attributes affecting water uptake of rice (Oryza sativa) under drought. - Journal of Experimental Botany 63: 4751-4763.

[10] Hund, A., Trachsel, S., Stamp, P. (2009): Growth of axile and lateral roots of maize: I development of a phenotying platform. - Plant and Soil 325: 335-349.

[11] IRRI, AfricaRice, CIAT (2010): Global Rice Science Partnership (GRiSP). International Rice Research Institute, Los BaLos Baños, Phillipines; Africa Rice Center, Cotonou, Benin; and International Center for Tropical Agriculture, Cali, Colombia.

[12] Lynch, J. P. (2007): Roots of the second green revolution. - Australian Journal of Botany 55: 493-512.

[13] Lynch, J. P. (2014): Root phenes that reduce the metabolic costs of soil exploration: opportunities for 21st century agriculture. - Plant Cell and Environment 38: 1775-1784.

[14] Lynch, J. P., Brown, K. M. (2001): Topsoil foraging - an architectural adaptation of plants to low phosphorus availability. - Plant and Soil 237: 225-237.

[15] Miguel, M. A., Postma, J. A., Lynch, J. P. (2015): Phene synergism between root hair length and basal root growth angle for phosphorus acquisition. - Plant Physiology 167: 1430-1439.

[16] Peña-Valdivia, C. B., Sánchez-Urdaneta, A. B., Rangel, J. M., Muñoz, J. J., García-Nava, R., Velázquez., R. C. (2010): Anatomical root variations in response to water deficit: wild and domesticated common bean (Phaseolus vulgaris L). - Biological Research 43: 41727.

[17] Pinheiro, L., Bates, D., DebRoy, S., Sarkar, D. (2012): The nlme package; linear and nonlinear mixed effects models. R Version 3.

[18] Postma, J. A., Lynch, J. P. (2010): Theoretical evidence for the functional benefit of root cortical aerenchyma in soils with low phosphorus availability. - Annals of Botany 107: 829-841.

[19] Rebouillat, J., Dievart, A., Verdeil, J. L., Escoute, J., Giese, G., Breitler, J. C., Gantet, P., Espeout, S., Guiderdoni, E., Périn. C. (2008): Molecular genetics of rice root development. - Rice 2: 15-34.

[20] Richards, R. A., Passioura, J. B., (1989): A breeding program to reduce the diameter of the major xylem vessel in the seminal roots of wheat and its effect on grain yield in rainfed environments. - Australian Journal of Agricultural Research 40: 943-950.

[21] Saengwilai, P., Nord, E., Chimungu, J., Brown, K. M., Lynch, J. P. (2014a): Root cortical aerenchyma enhances nitrogen acquisition from low nitrogen soils in maize (Zea mays L.). - Plant Physiology 166: 726-735.

[22] Saengwilai, P., Tian, X., Lynch, J. P. (2014b): Low crown root number enhances nitrogen acquisition from low-nitrogen soils in maize. - Plant Physiology 166: 581-589.

[23] Trachsel, S., Kaeppler, S. M., Brown, K. M., Lynch, J. P. (2010): Shovelomics: high throughput phenotyping of maize (Zea mays L.) root architecture in the field. - Plant and Soil 341: 75-87.

[24] Trachsel, S., Kaeppler, S. M., Brown, K. M., Lynch, J. P. (2013): Maize root growth angles become steeper under low N conditions. - Field Crops Research 140: 18-31.

[25] Tuberosa, R., Sanguineti, M. C., Landi, P., Giuliani, M. M., Salvi, S., Conti, S.(2002): Identification of QTLs for root characteristics in maize grown in hydroponics and analysis of their overlap with QTLs for grain yield in the field at two water regimes. Plant Molecular Biology 48: 697-712. 
[26] Uga, Y., Okuno, K., Yano, M. (2008): QTLs underlying natural variation in stele and xylem structures of rice root. - Breeding Science 58: 7-14.

[27] Uga, Y., Sugimoto, K., Ogawa, S., Rane, J., Ishitani, M., Hara, N., Kitomi, Y., Inukai, Y., Ono, K., Kanno, N., Inoue, H., Takehisa, H., Motoyama, R., Nagamura, Y., Wu, J., Matsumoto, T., Takai, T., Okuno, K., Yano, M. (2013): Control of root system architecture by DEEPER ROOTING 1 increases rice yield under drought conditions. Nature Genetics 45: 1097-102.

[28] Vejchasarn, P., Lynch, J. P., Brown, K. M. (2016) Genetic variability in phosphorus response of rice root phenotypes. - Rice 9: 1-29.

[29] Wailes, E. J., Chavez, E. C. (2012): ADB Sustainable Development Working Paper Series ASEAN and Global Rice Situation and Outlook. - Asian Development Bank, Manila, Philippines.

[30] Yambao, E. B., Ingram, K. T., Real, J. G. (1992): Root xylem influence on the water relations and drought resistance of rice. - Journal of Experimental Botany 43: 925-932.

[31] Zhan, A., Schneider, H., Lynch, J. P. (2015): Reduced lateral root branching density improves drought tolerance in maize. - Plant Physiology 168: 1603-1615.

[32] Zhu, J., Lynch, J. P. (2004): The contribution of lateral rooting to phosphorus acquisition efficiency in maize (Zea mays) seedlings. - Functional Plant Biology 31: 949-958.

[33] Zhu, J., Kaeppler, S., Lynch, J. P. (2005): Mapping of QTL controlling root hair length in maize (Zea mays L.) under phosphorus deficiency. - Plant and Soil 270: 299-310.

[34] Zhu, J., Brown, K. M., Lynch, J. P. (2010): Root cortical aerenchyma improves the drought tolerance of maize (Zea mays L.). - Plant Cell and Environment 33: 740-749. 